\title{
Algunas reinterpretaciones recientes. Breve revisión de la historiografía sobre el Yucatán de los siglos XIX y XX
}

\author{
Otbón Baños Ramírez \\ UNIVERSIDAD AUTÓNOMA DE YUCATÁN
}

\begin{abstract}
En este trabajo se destaca la vasta e importante bibliografía historiográfica sobre Yucatán que suele ser olvidada por los historiadores, sobre todo por aquellos que recogen, comparan y evalúan las experiencias regionales mexicanas.
\end{abstract}

\section{INTRODUCCIÓN}

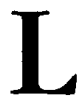

a rica historiografía yucateca que adquirió brillo y notoriedad durante el siglo XIX con las obras de Justo Sierra O'Reilly, Serapio Baqueiro, Eligio Ancona, Juan Francisco Molina, entre otros, ${ }^{1}$ parece poco conocida en el resto del país. Aparte del consabido egocentrismo cultural, hegemónico, del valle central, tal marginalidad en la discusión

${ }^{1}$ Sierra, Indios, 1954; Baqueiro, Ensayo, 1990; Ancona, Historia, 1978; Molina, Historia, 1921-1927. nacional más reciente ${ }^{2}$ se explicaría por la situación alejada de la región y por su reputación exagerada de regionalista y separatista.

No obstante, muchos jóvenes historiadores, insatisfechos con las generalizaciones existentes, forjadas desde el centro, particularmente acerca de los fenómenos socioeconómicos, han buscado en las últimas décadas poner a prueba tales generalizaciones del

${ }^{2} \mathrm{Al}$ menos esa impresión queda al revisar algunos ensayos sobre la historiografia regional mexicana, ejemplos: Pérez, Región, 1991, y Crespo, Historiador, 1992. 
nivel local. Muchos yucatecólogos, dice Joseph, se montaron en la ola denominada por algunos "revolución historiográfica", buscando un cambio en los enfoques históricos que partiría de la superestructura institucional para alcanzar el nivel de las regiones, las comunidades y hasta los grupos de presión local. ${ }^{3}$

Previamente, atraídos quizá por las glorias pasadas de la civilización maya, por la guerra de Castas, por el auge del henequén, por el socialismo criollo de Carrillo Puerto y por otros muchos eventos sociales, algunos antropólogos llevaron a cabo estudios en Yucatán que han llegado a tener una significación muy grande dentro del paradigma del conocimiento latinoamericano. Tal es el caso de la obra de Robert Redfield y sus colaboradores. En su libro intitulado The folk culture of Yucatan, Redfield se esfuerza por mostrar la coexistencia y la coalescencia de rasgos culturales heterogéneos, tanto indígenas como españoles. No viene aquí al caso entrar en detalle en su idea del continuum cultural folk-urbano. ${ }^{4}$ Según Guillermo de la Peña, el valor del esquema redfieldiano se muestra, sobre todo, en que pudo generar un enorme volumen de investigación social que trascendía el ámbito comunitario y que mostraba una lógica en los procesos de cambio y las relaciones entre las comunidades. $^{5}$

El objetivo principal de este trabajo es señalar que, al colocarse los estu-

\footnotetext{
${ }^{3}$ Joseph, Guerra, 1987.

Véase Redfield, Folk, 1941.

s Peña, "Estudios", 1991, p. 136.
}

dios regionales, a principios de la década de los setenta, en el primer plano de la investigación de la historia de México, pronto aparecieron algunas aportaciones basadas en la experiencia de Yucatán. Ya sea como un caso lindante con otro mayor o como un componente dinámico de una entidad macro, la nueva historiografía regional ha venido iluminando discusiones más amplias sobre la historia política, social y cultural de México.

Este auge de la "nueva historiografia" yucateca, vino acompañado de un mejoramiento en los archivos y bibliotecas, del esfuerzo de las instituciones académicas y, sobre todo, del entrenamiento profesional. ${ }^{6}$

Hoy día, la historiografía sobre Yucatán parece apoyarse, en términos generales, en la suposición básica de que, al conferírsele una gran valoración heurística al enfoque regional, se puede reintepretar y con ello enriquecer la historia de México. El concepto clave es región: ¿qué son las regiones? y icómo ha sido estudiada esta región por los historiadores? Rigurosamente, ambas preguntas merecen una respuesta amplia, como la que ofrece Eric van Young en su ensayo intitulado "Haciendo historia regional: consideraciones metodológicas y teóricas". 7 Para el caso de Yucatán, hace falta una exhaustiva investigación ex profeso actualizada.

El primer paso ya fue dado por Joseph ${ }^{8}$ quien señala que los eventos más estudiados son: la guerra de Cas-

\footnotetext{
'Joseph, Guerra, 1987, p. 11.

7 Véase Pérez, Región, 1991.

${ }^{\mathrm{B}}$ Joseph, Rediscovering, 1986.
} 
tas, las haciendas y la oligarquía henequeneras, el socialismo de Carrillo Puerto y de Alvarado y el proceso de la reforma agraria. Más recientemente, las investigaciones se han focalizado hacia las clases y los sujetos sociales: campesinos, empresarios, clero y elites políticas. 'Asimismo, se han añadido otros enfoques, como el de la influencia de las ideas en la formación de los actores políticos, y otros temas, como el del surgimiento de las instituciones liberales. ${ }^{10}$

En suma, la nueva historiografía regional ha iluminado discusiones más amplias sobre las rebeliones campesinas, la expansión agrícola capitalista, las comunidades campesinas, los sistemas de plantaciones de monocultivo y sus posibilidades de desarrollo regional, así como la movilización revolucionaria, la conformación de grupos de poder y la estrategia de cambio social.

De todas maneras, los historiadores también vuelven a los temas tradicionales: por la propia naturaleza dinámica del proceso del conocimiento, por la valoración de nuevas fuentes de archivos, por el surgimiento de nuevos enfoques y por el influjo de la problemática del presente. Además, porque, según Joseph, que ha examinado con bastante profundidad dicha bibliografía, los yucatecólogos han explorado más allá de sus fuentes usuales, que son la prensa regional y las colecciones de folletería raras. En-

9 Baños, Yucatán, 1989; Ramírez, Secretos, 1994; Wells, Yucatan's, 1985; Menéndez, Iglesia, 1995; Sabido, Hombres, 1995.

${ }^{10}$ Baños, Liberalismo, 1995. tre otras, registros parroquiales y archivos notariales, localizando ahí títulos de propiedad, registros de pleitos, censos agrarios y listas de impuestos; han recogido tradición oral y registros escritos mayas, etcétera. ${ }^{11}$

\section{ALGUNAS REINTERPRETACIONES}

No es posible enlistar todos y cada uno de los trabajos publicados clentro de esta nueva perspectiva historiográfica regional y, mucho menos, colocarlos en un orden cronológico. ${ }^{12}$ En cambio, fueron seleccionados algunos autores (con la injusticia que supone para los demás), especialmente aquellos que parecen ejemplificar la nueva interpretación de la historiografía yucateca.

\section{La guerra de Castas}

Los historiadores criollos yucatecos más notables, como Eligio Ancona, Serapio Baqueiro y Juan Francisco Molina Solís quienes, en opinión de Melchor Campos, siguen muy de cerca la vena abierta por Justo Sierra O'Reilly, ${ }^{13}$ argumentan en sus respectivas obras que el estallido de la guerra de 1847 se debió principalmente

${ }^{11}$ Joseph, Guerra, 1987, p. 14.

12 Hay que señalar, no obstante, que son, principalmente, los investigadores "foráneos" (de instituciones localizadas fuera de Yucatán) los que han seguido de cerca dicha vanguardia, más ampliamente caracterizada por Joseph, Rediscovering, 1986.

${ }^{13} \mathrm{~A}$ través de sus artículos en El Fétix. Comunicación personal, 2 de mayo de 1996. 
al etnocentrismo indígena: al bien conocido odio de los mayas hacia los extranjeros alimentado por varios siglos de dominio europeo.

Justo Sierra O'Reilly, un contemporáneo de los acontecimientos, anotó la importancia de las leyes sobre tenencia de la tierra como el factor que había provocado el levantamiento. Sin embargo, los historiadores pasaron por alto este factor y sostuvieron que la guerra fue, en esencia, nada más que la reanudación del viejo conflicto entre indígenas y blancos. En la década de los cuarenta, Howard F. Cline ${ }^{14}$ rescató del olvido la interpretación de Sierra e hizo de la problemática agraria el punto central de su interpretación de la guerra de Castas. ${ }^{15}$

Más tarde, en los setenta, aparecieron otros estudios en esa misma dirección, como los de Moisés González Navarro, Robert Patch, Marie Lapointe y Victoria Bricker. ${ }^{16} \mathrm{La}$ exploración de nuevas fuentes, como el Archivo General del Estado y el Archivo Notarial del Estado, a las que no tuvieron acceso ni Cline ni los otros autores mencionados, permitieron a Robert Patch revisar críticamente la hipótesis de los historiadores que lo habían precedido. Concluyó así que, la llamada guerra de Castas, fue el resultado de un proceso dialéctico provocado por la expansión agrícola comercial y la respuesta a ésta de los mayas libres. Pre-

${ }^{14}$ Cline, "Regionalism", 1947. 47-48.

"Véase Patch, "Descolonización", 1990, pp.

${ }^{16}$ González, Raza, 1970; Patch, "Colonial", 1979; Lapointe, Mayas, 1983; Bricker, Cristo, 1989. cisó que una de sus causas principales fue el rápido cambio agrario impulsado por el gobierno después de la independencia: la transformación de, cuando menos, 600 mil hectáreas de tierra en propiedad privada, amenazó el modo de vida de la comunidad maya como nunca antes en tres siglos de conquista.

Además, la disposición de armas por parte de ésta, fue otro factor importante: durante la contienda política de 1840, y debido al hostigamiento del gobierno central, las facciones rivales comenzaron, en su desesperación, a armar a los indígenas para que sirvieran como soldados en sus ejércitos. ${ }^{17}$ Eventualmente, la distribución de armas fue tan grande y tan amplias las posibilidades de conseguir más a través de Belice, que el levantamiento maya tuvo la posibilidad de luchar en igualdad de pertrechos con el ejército. ${ }^{18}$ Este episodio, así como muchos otros que se dieron en el país a mediados del siglo XIx, reflejan de manera fidedigna las contradicciones del sistema social de la época. ${ }^{19}$

\section{El socialismo criollo}

La figura y el gobierno de Felipe Carrillo Puerto han sido estudiados descle diversos ángulos y perspectivas por los historiadores yucatecos; pero la mayoría de ellos lo han hecho tratando de explicar cómo arribó al poder y

\footnotetext{
${ }^{17}$ Zuleta, "Federalismo", 1995, pp. 27-33.

${ }^{18}$ Patch, "Descolonización", p. 85.

${ }^{19}$ Reina, Rebeliones, 1984.
} 
por qué fue asesinado. ${ }^{20}$ Nadie parece preocupado por el contexto social, regional y nacional y, en consecuencia, por el alcance histórico de dicho fenómeno a nivel más amplio.

Uno de los primeros trabajos publicados dentro de la nueva perspectiva historiográfica apareció en la ciudad de México en 1977: El socialismo olvidado de Yucatán, de Francisco Paoli Bolio y Enrique Montalvo. En él se rescata la aparición y el protagonismo histórico del Partido Socialista del Sureste, bajo el liderazgo indiscutible de Felipe Carrillo Puerto. Este trabajo contribuyó a la comprensión del panorama político mexicano posrevolucionario, pues el PSSE, más que estudiado había sido mitificado y oscurecida su auténtica significación social. ${ }^{21}$

Las categorías populista y popular fueron utilizadas aquí como ejes de interpretación de un proceso que, según los autores, es el de la formación y el desarrollo de las clases sociales. Para ellos se trata de las formas distintas en que asumen el Estado, los partidos, los movimientos y las ideologías políticas dentro de una formación capitalista dada, de acuerdo con las distintas alianzas y oposiciones entre las clases y las fracciones de éstas. Por ejemplo, el Estado populista sería aquel controlado por oligarquías tradicionales más o menos barnizadas de ideologías liberales. El Estado popular en cambio, se caracteriza por la aparición, cada vez más sistemática, de acciones organizadas por el proletariado, su ideología y sus instrumentos

${ }^{20}$ Sosa, Crimen, 1969.

${ }^{21}$ Paoli y Montalvo, Socialismo, 1977, p. 7. políticos y sindicales. ${ }^{22}$ Los autores llegan a la conclusión de que el psse fue un partido popular y, en consecuencia, el gobierno de Felipe Carrillo Puerto también lo fue. Por cuestionar entonces la ideología burguesa, por ir en contra del statu quo, fueron muchas las actividades desarrolladas por el gobierno del PSSE que aparecían como subversivas, a pesar de haber alcanzado ya el gobierno. ${ }^{23}$

\section{La revolución y el nuevo Estado}

En Yucatán y los orígenes del nuevo Estado mexicano, Paoli $^{24}$ se propuso elaborar una visión de conjunto e histórica de la praxis política de Yucatán en el periodo de 1915-1917, la cual, según él, habría contribuido, de manera significativa, a la conformación del Estado nacional. Es un esfuerzo bastante bien logrado para dotar de una dimensión analítica más amplia y objetiva a las experiencias políticas regionales durante el complejo proceso de conformación del nuevo Estado mexicano a partir del triunfo de la fracción carrancista.

Según Paoli, para entender el actual Estado nacional posrevolucionario se requiere, en alguna medida, de analizar sus orígenes, las fuerzas sociales que lo prefiguraron y que persisten hasta hoy, y los modelos políticos e ideológicos que entreveraron la génesis estatal.

\footnotetext{
${ }^{22}$ Ibid., p. 24.

${ }^{23}$ Ibid., p. 172.

${ }^{24}$ Paoli, Yucatän, 1984.
} 
El planteamiento teórico, que permite al autor superar el alcance de la profusa historiografía existente acerca del general Salvador Alvarado en Yucatán, es que los aportes de la experiencia yucateca son señeros en el periodo de gestación del nuevo Estado. Por tanto, el interés central no es la biografia del general, sino la sociedad y el Estado yucatecos existentes durante el periodo de gobierno preconstitucional.

El mérito de esta obra no está, pues, en la exploración de nuevas fuentes o archivos, sino en que el autor hace un análisis de hechos ampliamente documentados, como son los cambios promovidos en la esfera económica, social, política y cultural que indujo dicho gobernante.

La estructura analítica de la obra está montada sobre dos grandes unidades de análisis: el hombre (culto y carismático) y sus ideas, por un lado, y la sociedad y sus condiciones, por otro. Para Paoli, la capacidad intelectual y política adquirida previamente por Alvarado en otro contexto, le permitió no llegar a hacer méritos, sino a realizar transformaciones de amplias proporciones. Por otra parte, la capacidad de la economía estatal, basada en la producción de henequén, permitía generar una cantidad importante de recursos, que fueron un pilar fundamental para que la autonomía política se ejerciera sin limitaciones estrechas.

\section{Otro enfoque de la revolución en Yucatán}

La revolución desde fuera, de Gilbert M. Joseph, se inscribe también dentro de la nueva tendencia de la historiografía de la revolución mexicana: de la que ha incursionado en los procesos regionales, que ha dejado de lado la idea de una revolución nacional y que considera que este proceso fue más bien un mosaico de experiencias locales, con trasfondo común pero provenientes de orígenes muy diversos.

Esta obra ${ }^{25}$ tardó, desafortunadamente, diez años en estar al alcance del hablante en español, pues apareció originalmente publicada en inglés en el año de 1982, dentro de la colección de Cambridge University Press y, posteriormente, en 1988, cuando fue reeditada por la Duke University Press. La traducción al español cstuvo a cargo de Eduardo L. Suárez.

No obstante, es un hecho que la revolución sigue siendo uno de los temas más estudiados en la producción historiográfica de los últimos años. Incluso a raíz de las diferentes interpretaciones dadas a conocer en las últimas décadas y de las discusiones que han suscitado, se ha renovado el interés por el México porfiriano y revolucionario, buscando iluminar la relación que guardan entre sí csos dos periodos históricos, en contra de las apreciaciones nacionalistas que veían una ruptura entre ambos regímenes.

El principal elemento de las nuevas interpretaciones en estudios regionales, como el de Joseph, ha sido, desde los años sesenta, el de analizar la estructura social, económica y política en forma acuciosa, dándole con ello un contenido más matizado a las grandes discusiones teóricas.

\footnotetext{
25 Joseph, Revolución, 1992.
} 
Un aspecto, sin duda sobresaliente y que debe señalarse, es que dicha obra es una investigación muy bien documentada. El autor revisó la bibliografía más relevante sobre el tema y consultó igualmente los archivos más importantes tanto nacionales como locales; el Archivo General de la Nación, el Archivo General del Estado y algunos archivos privados; también estadunidenses, especialmente el archivo de la Internacional Harvester y la Plymouth Cordage Co., que eran los compradores más importantes de la fibra de henequén yucateca. Con esta documentación, Joseph consigue ver desde dentro y desde fuera los intereses y contradicciones que alimentaron el proceso revolucionario en esta región del país.

Desde la óptica teórica, el trabajo está guiado, al parecer, por la pregunta: ¿por qué fracasa una revolución social ahí donde más se necesita? El argumento es que una revolución que no logra penetrar entre las clases populares que precisan de ella mayormente, limitada en sus alcances, y que procede desde fuera y desde arriba, no cala en profundidad o, sencillamente, se transforma en mito. Pero es cierto también que las revoluciones sociales en Latinoamérica no sólo han fracasado debido a las condiciones internas: Estados Unidos ha contribuido mucho a ello de diversas maneras. En este caso el autor muestra claramente que la revolución en Yucatán fracasó, como después han fracasado las revoluciones en Chile, Nicaragua y otros países latinoamericanos, debido a la intervención imperialista estadunidense. Cuba ha sido una digna excepción a este "destino manifiesto".

Para analizar los logros y fracasos de la revolución en Yucatán, el autor sigue dos grandes ejes de análisis: 1) el de las condiciones económicas y sociales de la región, fuertemente influidas por el monocultivo henequenero, y 2) el de los intereses externos a la región, ya fueran los del gobierno central o del estadunidense.

Este contrapunteo entre los intereses locales, nacionales y estadunidenses resulta útil para el lector porque le permiten comprender la verdadera dimensión del proceso. Como dice Alan Knight en su presentación,

en Revolución desde afuera, el autor hace justicia al carácter distinto cle Yucatán $[\ldots]$, pero no se refugia en la oscuridad ideográfica: el exotismo de la patria chica no le oculta lo que hay también de general o incluso universal en la historia de la península. ${ }^{26}$

\section{Otros enfoques más recientes}

Otra veta que ha dado pie a nucvas reinterpretaciones historiográficas son las doctrinas sociales, como por ejemplo el liberalismo. El hecho de que México estrenara su vida independiente a la luz del paradigma liberal, marcó sin duda el horizonte hacia el cual se proyectó la energía social. ${ }^{27}$ Betancourt y Villarreal, Güémez Pineda, Zuleta Miranda y Cam-

\footnotetext{
${ }^{26}$ Joseph, Rediscovering, 1986, p. 9.

${ }^{27}$ Betancourt y Sierra, Yucatán, 1989; Güémez, Liberalismo, 1994; Campos, "Política", 1995; Zuleta, "Federalismo", 1995.
} 
pos García (1995), entre otros, revisan críticamente los diferentes movimientos y grupos políticos para determinar qué papel jugó la clase política yucateca en el accidentado proceso de formación del Estado mexicano a partir del movimiento de independencia. Güémez, en su trabajo intitulado Liberalismo en tierras del caminante. Yucatán 1812-1840, nos ofrece una caracterización de la política agraria yucateca. La disputa central se dio en torno al recurso fundamental, la tierra. Las formas de tenencia y su uso, dividió frecuentemente a la clase dominante. El autor demuestra y explica cómo cada facción de la misma, dependiendo muchas veces de la coyuntura nacional (dominada por federalistas o centralistas), se instalaba en el poder y promulgaba leyes en favor de sus intereses, las cuales eran más tarde modificadas o derogadas por el grupo de poder triunfante. Todos ellos, no obstante, tuvieron algo en común: su fe proverbial en la propiedad privada y su desprecio por las comunidades indígenas. La primera simbolizaba para ellos el progreso y las segundas el atraso. Seguir las huellas de la propagación de las ideas liberales a través de las leyes agrarias, permite además al autor ligar los acontecimientos que afloran en el viejo continente con los que se producen en Nueva España.

El texto proporciona también una magnífica aproximación a la convulsa sociedad yucateca de principios del siglo XIX, así como al acomodo de las nuevas y viejas ideas a los intereses de los diferentes grupos de poder. Ciertamente, hubo de todo un poco: gru- pos proautonomistas, procentralistas, profederalistas, proseparatistas, entre otros.

En la coyuntura abierta por el movimiento de independencia, los yucatecos buscaron qué hacer para impulsar el desarrollo y para ello se apoyaron en las ideas liberales provenientes del viejo continente. Así, hacia dentro impulsaron la propiedad privada, pero hacia fuera, desde la ruptura con la metrópoli española, Yucatán inició una conflictiva relación con el resto de lo que había sido el territorio de Nueva España: la clase política yucateca intentó obtener de él una serie de condiciones comerciales y administrativas que le garantizaran una situación de excepción respecto al resto de los estados de la república. ${ }^{28}$

\section{ALGUNOS RETOS DE LA HISTORIOGRAFÍA} REGIONAL EN YUCATÁN

Se puede decir que, a principios de los setenta, se inició en Yucatán un periodo de profesionalización de la investigación en el área de ciencias sociales, particularmente en historia. Anteriormente, la historiografía era realizada por personas muy bien entrenadas en otras disciplinas afines, pero no estaban preparadas ni teórica ni metodológicamente para reconstruir la historia social regional. En el decenio de los setenta hubo cambios importantes: los historiadores se convencieron, como dice don Luis González, de que la historia no es aquella que se hace con base en ideas o sim-

\footnotetext{
${ }^{28}$ Zuleta, "Federalismo", 1995, p. 23.
} 
ples deseos, sino la que se fundamenta en documentos. ${ }^{29}$

No es casual, entonces, que se haya generado un auge en investigaciones referidas a la dimensión regional, como las señaladas antes. Y ya que México, como nación, está muy lejos de ser una entidad homogénea, este factor supone un gran reto teórico, no sólo para la historia sino también para las ciencias sociales. En la investigación realizada en provincia, estudiar las especificidades locales y, al mismo tiempo, contextualizarlas dentro del conjunto nacional, es una tarea todavía en ciernes. No se trata, además, solamente de caracterizar la diversidad ${ }^{30}$ sino de contribuir teóricamente a su transformación para disminuir las inequidades.

Como señala Romero, ${ }^{31}$ si algo está claro en el campo de los estudios latinoamericanos es que carecemos de un sistema de conceptuación apto para replantear rigurosamente los problemas que deben ser sometidos al análisis histórico. Enfrentados con una vasta realidad compleja y difusa, nos hallamos desprovistos de claves para introducirnos en ella, comenzar a desbrozarla y lograr la claridad suficiente para saber que lo que sometemos a examen son campos homogéneos, fenómenos comparables y situaciones verdaderamente significativas.

Pese a los innegables avances, la historia mexicana está en espera de

\footnotetext{
${ }^{29}$ González, "Historiografía", 1992. 1992.

${ }^{30}$ A este respecto véase Tejera, "Identidad",

${ }^{31}$ Romero, "Campo", 1981, p. 25.
}

un riguroso replanteamiento de su problemática general, por encima de la problemática regional, pero sin clesprenderse de ésta y escapando de generalizaciones imprecisas y mecánicas. Se requiere de primeros niveles de abstracción bien realizados y sobre información de primera mano.

El esfuerzo desplegado, con muy pocas excepciones, no ha logrado superar los grandes problemas teóricometodológicos que repetidamente enfrenta el enfoque regional, ${ }^{32}$ algunos de los cuales son: la relación entre lo particular y lo general, es decir, los alcances o grados de generalización de las investigaciones en cuanto a la com. prensión de los fenómenos socioculturales de nuestro país; entre lo estructural y lo coyuntural; entre las continuidades y rupturas de los procesos sociales, así como la forma de diferenciar unos de otros; entre lo homogéneo y lo diverso en las tendencias históricas y de desarrollo, etcétera.

$$
\text { Mérida, Yucatán, } 1997 .
$$

\section{BIBLIOGRAFÍA}

-Ancona, Eligio, Historia de Yucatán, s. e., 1878-1880, ed. facsimilar Universiclad Autónoma de Yucatán, Mérida, 1978, 4 vols.

-Baños Ramírez, Othón, Yucatán: ejidos sin campesinos, Universidad Autónoma de Yucatán, Mérida, 1989.

\footnotetext{
${ }^{32}$ Entendiendo que las regiones no existen a priori, sino que hay que definirlas como hipótesis de trabajo (Van Young, "Haciendo", 1991, pp.100-101).
} 
(comp.), Liberalismo, actores y política en Yucatán, Universidad Autónoma de Yucatán, Mérida, 1995.

-Baqueiro, Serapio, Ensayo bistórico sobre las revoluciones de Yucatán, desde el año de 1840 basta 1864, s. e., 1878 . 1887 , ed. facsimilar Universidad Autónoma de Yucatán, Méricla, 1990, 5 vols.

-Betancourt Pérez, Antonio y José Luis Sierra Villarreal, Yucatán: una bistoria compartida, SEP/Instituto Mora, México, 1989.

-Bricker, Victoria, El cristo indígena, el rey nativo. El sustrato bistórico de la mitología ritual de los mayas, $\mathrm{FCE}, \mathrm{Mé}-$ xico, 1989.

-Campos García, Melchor, "La política yucateca en una etapa de crisis económica. Regionalismo, autonomía y separatismo, 1808-1835", tesis de maestría, Facultad de Filosofía y Letras, UNAM, México, 1995.

-Cline, Howard, "Regionalism and society in Yucatan: 'Progresivism' and the origins of the Caste war 1825-1847", tesis de doctorado, Harvard University, 1947.

-Crespo, Horacio y otros, El historiador frente a la bistoria, UNAM, México, 1992.

-González Navarro, Moisés, Raza y tierra. La guerra de Castas y el benequén, El Colegio de México, México, 1970.

-González y González, Luis, "La historiografia que nos rodea" en Horacio Crespo y otros, El bistoriador frente a la bistoria, UNAM, 1992.

-Güémez Pineda, Arturo, Liberalismo en tierras del caminante: Yucatán 18121840, El Colegio de Michoacán/Universidad Autónoma de Yucatán, Zamora, Mich., 1994.

-Joseph, Gilbert M., Rediscovering the past at Mexico's periphery: ensays on the bistory of modern Yucatán, Alabama University Press., Tuscaloosa, Al., 1986.

- De la guerra de Castas a la

lucha de clases. La bistoriografía del
Yucatán moderno (1750-1940), ed. especial El Diario del Sureste, 1987.

Revolución desde fuera. Yucatán, México y los Estados Unidos, 1880-1924, FCE, México, 1992.

-Lapointe, Marie, Los mayas rebeldes de Yucatán, El Colegio de Michoacán, Zamora, Mich., 1983.

-Menéndez Rodríguez, Hernán, Iglesia $y$ poder. Proyectos sociales, alianzas politicas y económicas en Yucatán, Consejo Nacional para la Cultura y las Artes, México, 1995.

-Molina Solís, Juan Francisco, Historia de Yucatán desde la independencia de España basta la época actual, s. e., Mérida, 1921-1927.

-Paoli Bolio, Francisco, Yucatán y los orígenes del nuevo Estado mexicano, Ediciones Era, México, 1984.

- y Enrique Montalvo Ortega, El socialismo olvidado en Yucatán, Siglo XXI Editores, México, 1977.

-Patch, Robert, "Descolonización, el problema agrario y los orígenes cle la guerra de Castas, 1812-1847" en Othón Baños Ramírez, Sociedad, estructura agraria y estado en Yucatán, Universidad Autónoma de Yucatán, Mérida, 1990.

$\longrightarrow$ "A colonial regime: maya and spaniard in Yucatan", tesis de doctorado, Princeton University, 1979.

-Peña, Guillermo de la, "Los estudios regionales y la antropología social en México" en Pedro Pérez Herrero (comp.), Región e Historia en México (1700-1850), Instituto Mora/Universidad Autónoma Metropolitana, México, 1991.

-Pérez Herrero, Pedro (comp.), Región $e$ bistoria en México (1700-1850), Instituto Mora/Universidad Autónoma Metropolitana, México, 1991.

-Ramírez Carrillo, Luis A., Secretos de familia. Libaneses y elites empresariales en Yucatán, Consejo Nacional para la Cultura y las Artes, México, 1994. 
-Redfield, R., The folk culture of Yucatan, University of Chicago Press, Chicago, 1941.

-Reina, Leticia, Las rebeliones campesinas en México, 1819-1906, Siglo XXI Editores, México, 1984.

-Romero, José Luis, "Campo y ciudad: las tensiones entre dos ideologías" en varios autores, Cultura y sociedad en América Latina y el Caribe, UNESCO, Vendome, Francia, 1981.

-Sabido Méndez, Arcadio, Los bombres del poder. Monopolios, oligarquía y riqueza en Yucatán, 1880-1890, Universidad Autónoma de Yucatán, Mérida, 1995.

-Sierra O'Reilly, Justo, Los indios de Yucatán, s. e., Mérida, 1954.2 vols.

-Sosa Ferreyro, Roque Armando, $\mathrm{El} \mathrm{cri-}$ men del miedo, Costa-Amic, México, 1977.
-Tejera Gaona, Héctor, "La identidad cultural y el análisis regional", Nueva Antropología, vol. XXI, núm. 41, marzo, 1992.

-Welles, Alan, Yucatán's gilded age: baciendas, benequen and International Harvester, 1860-1915, University of New Mexico Press, Albuquerque, 1985.

-Young, Eric van, "Haciendo historia regional: consicleraciones metodológicas y teóricas" en Pedro Pérez Herrero (comp.), Región e bistoria en México (1700-1850), Instituto Mora/UAM, México, 1991, pp. 99. 122.

-Zuleta Miranda, María Cecilia, "LI federalismo en Yucatán: política y militarización (1840-1846)", Secuencia, Instituto Mora, núm. 31, enero-abril, 1995. 


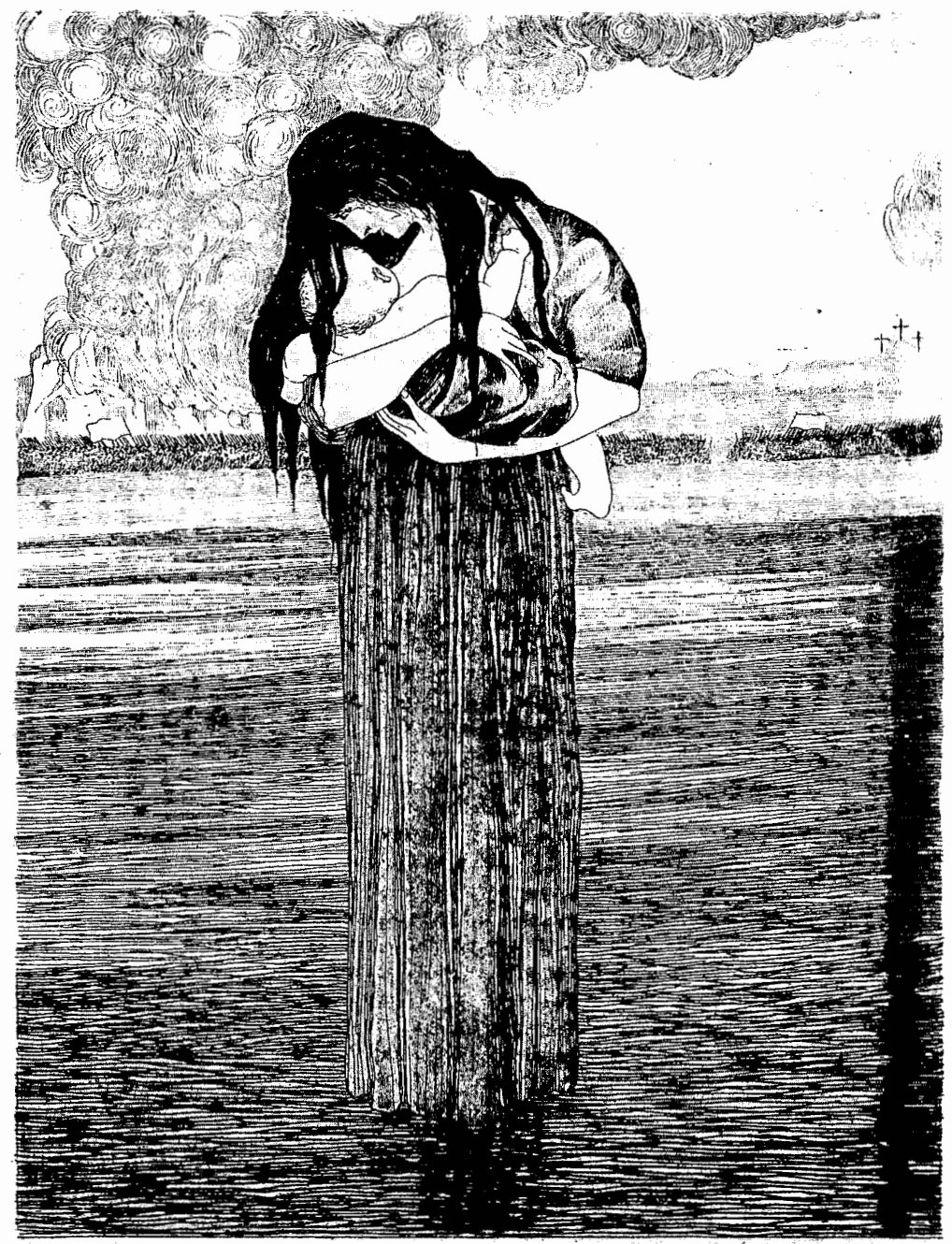

\section{CADMEN DOMENECH A GDAS EXLIBDIS}

